\title{
Somatic paravertebral block decreases opioid requirements in children undergoing appendectomy
}

\section{Les blocs paravertébraux des nerfs somatiques réduisent les besoins en opioïdes chez les enfants subissant une appendicectomie}

\author{
William M. Splinter, MD • Margaret E. Thomson, BSc
}

Received: 28 July 2009/ Accepted: 19 November 2009/Published online: 9 January 2010

(c) Canadian Anesthesiologists' Society 2009

\begin{abstract}
Purpose Somatic paravertebral block (SPVB) appears to provide effective and prolonged nerve block in children; however, study of its use in this population is limited. We compared SPVB with no block in children undergoing appendectomy.

Methods Thirty-six children aged 3-16 yr undergoing open appendectomy were involved in this prospective randomized controlled study. Anesthesia was induced with propofol and maintained with isoflurane in $\mathrm{N}_{2}$ Oloxygen. All subjects received fentanyl, acetaminophen and ketorolac during anesthesia. Group I (SPVB) subjects received a right $S P V B$ at $T_{11}, T_{12}$, and $L_{1}$ using $0.2 \%$ ropivacaine $0.25 \mathrm{~mL} \cdot \mathrm{kg}^{-1}$ with epinephrine 1:200,000 preoperatively. Group II (Control) had only bandaids applied to skin. Both groups were given morphine $0.05 \mathrm{mg} \cdot \mathrm{kg}^{-1}$ iv every $2 \mathrm{hr}$ if pain scores reached $5 / 10$ on a visual analogue scale. Acetaminophen was administered postoperatively every 6 $\mathrm{hr}$ to both groups. Time to first dose of morphine, total dose of morphine in $24 \mathrm{hr}$, and any adverse effects up to $24 \mathrm{hr}$ after surgery were recorded.

Results Group I (SPVB) subjects required significantly less morphine than Group II (Control) patients $(0.12 \pm 0.07$ vs $0.34 \pm 0.15 \mathrm{mg} \cdot \mathrm{kg}^{-1}$, respectively; $\left.P<0.001\right)$, and time to their first dose was significantly longer $(7.1 \pm 4.4 \mathrm{vs}$ $2.5 \pm 1.6 \mathrm{hr}$, respectively; $P<0.001)$. Incidence of vomiting was $11 \%$ with Group I and $27 \%$ with Group II $(P=0.21)$. No other adverse effects were observed in either group.
\end{abstract}

W. M. Splinter, MD $(\bowtie) \cdot$ M. E. Thomson, BSc

Department of Anesthesia, Children's Hospital of Eastern

Ontario, University of Ottawa, 401 Smyth Rd, Ottawa, Ontario

K1H 8L1, Canada

e-mail: splinter@cheo.on.ca
Conclusions In children undergoing appendectomy, $S P V B$ provides better pain relief than no block and reduces opioid requirements. Side effects were not statistically different between groups.

\section{Résumé}

Objectif Les blocs paravertébraux des nerfs somatiques (BPVS) semblent procurer un bloc nerveux efficace et prolongé chez les enfants; toutefois, les études examinant son utilisation chez cette population sont peu nombreuses. Nous avons comparé l'utilisation d'un BPVS à une technique sans bloc chez des enfants subissant une appendicectomie.

Méthode Trente-six enfants âgés de 3 à 16 ans et subissant une appendicectomie ouverte ont participé à cette étude randomisée contrôlée prospective. L'anesthésie a été induite à l'aide de propofol et maintenue avec de l'isoflurane et du $\mathrm{N}_{2} \mathrm{O} /$ oxygène. Tous les patients ont reçu $d u$ fentanyl, de l'acétaminophène et du kétorolac pendant l'anesthésie. Les patients du Groupe I (BPVS) ont reçu un BPVS droit aux niveaux $T_{11}, T_{12}$, et $L_{1}$ avec $0,25 \mathrm{~mL} \cdot \mathrm{kg}^{-1}$ de ropivacaïne à 0,2\% et de l'épinéphrine 1:200 000 avant l'opération. Dans le Groupe II (témoin), seuls des pansements ont été appliqués sur la peau. Les deux groupes ont reçu de la morphine $0,05 \mathrm{mg} \cdot \mathrm{kg}^{-1}$ iv toutes les $2 \mathrm{~h}$ si les scores de douleur atteignaient $5 / 10$ sur une échelle visuelle analogique. Après l'opération, de l'acétaminophène a été administrée toutes les $6 \mathrm{~h}$ aux deux groupes. Le temps écoulé jusqu'à la première dose de morphine, la dose totale de morphine en 24 h et tous les effets indésirables observés jusqu'à 24 h après la chirurgie ont été enregistrés.

Résultats Les patients du Groupe I (BPVS) ont manifesté des besoins en morphine significativement moins prononcés que les patients du Groupe II (témoin) $(0,12 \pm$ 0,07 vs $0,34 \pm 0,15 \mathrm{mg} \cdot \mathrm{kg}^{-1}$, respectivement; $P<0,001$ ), 
et le temps écoulé jusqu'à la première dose était significativement plus long dans le Groupe I (7,1 \pm 4,4 vs $2,5 \pm 1,6 \mathrm{~h}$, respectivement; $P<0,001)$. L'incidence de vomissements était de $11 \%$ dans le Groupe I et de $27 \%$ dans le Groupe II $(P=0,21)$. Aucun autre effet secondaire n'a été observé dans l'un ou l'autre groupe.

Conclusion Pour les enfants subissant une appendicectomie, le BPVS procure un meilleur soulagement de la douleur que l'absence de bloc et réduit les besoins en opioïdes. Les effets secondaires n'étaient pas statistiquement différents entre les groupes.

Pain and the fear of pain are common and major concerns of children undergoing surgery. Pediatric appendectomy is a common procedure and is associated with moderate to severe postoperative pain. There are numerous options to reduce pain after appendectomy. Somatic paravertebral block (SPVB) is a unique method of nerve block near the origin of the nerves from the spinal canal. The paravertebral space lies between the heads and necks of two consecutive ribs where spinal nerves can be blocked by the injection of a local anesthetic agent. Somatic paravertebral block provides prolonged duration of action and a high margin of safety. ${ }^{1-12}$ While the technique has been shown to be effective and safe in children undergoing certain procedures, including thoracotomies and urological surgeries, ${ }^{1-8}$ the study of its use is limited in this age group and more specifically in pediatric appendectomies. Somatic paravertebral block has been demonstrated to provide effective analgesia in adults for a variety of procedures, including unilateral thoracic and abdominal surgeries, and to offer pain relief with minimal undesirable effects compared with epidural, intercostal, or intrapleural analgesia. ${ }^{8-12}$

This study compared SPVB with no block and examined postoperative analgesic requirements as the primary endpoint in children undergoing open appendectomy. We hypothesized that SPVB would provide superior and prolonged pain relief and would minimize opioid requirements in the postoperative period.

\section{Methods}

With the Children's Hospital of Eastern Ontario's Research Ethics Committee's approval and parental consent, we studied 36 children aged 3-16 yr undergoing open appendectomy. Exclusion criteria included cardiac disease, developmental delay, neurologic deficit, or allergies to any of the drugs routinely used in anesthesia management.

Induction of anesthesia was performed using propofol $2.5 \mathrm{mg} \cdot \mathrm{kg}^{-1}$ and succinylcholine $1.5 \mathrm{mg} \cdot \mathrm{kg}^{-1}$ or rocuronium $1.2 \mathrm{mg} \cdot \mathrm{kg}^{-1}$. Anesthesia was maintained with $1 \%$ isoflurane end-tidal in $70 \% \mathrm{~N}_{2} \mathrm{O}$ and oxygen. Ventilation was controlled to maintain an end-tidal $\mathrm{CO}_{2}$ from 35 to $40 \mathrm{mmHg}$. All patients received fentanyl $2 \mu \mathrm{g} \cdot \mathrm{kg}^{-1} i v$ and acetaminophen $40 \mathrm{mg} \cdot \mathrm{kg}^{-1} \mathrm{pr}$ (to a maximum of $1300 \mathrm{mg}$ ) at the start of surgery. A random number table was used to assign patients to a study group. Patients who were randomly assigned an even number were placed in Group I (SPVB group), while patients assigned an odd number were placed in Group II (Control group).

After induction of anesthesia, all patients were placed in the left lateral decubitus position. Group I patients received a right somatic paravertebral block at three sites, $\mathrm{T}_{11}, \mathrm{~T}_{12}$, and $\mathrm{L}_{1}$, using $0.2 \%$ ropivacaine with epinephrine 1:200,000, $0.25 \mathrm{~mL} \cdot \mathrm{kg}^{-1}$ to a maximum of $5 \mathrm{~mL}$ at each level before the start of surgery. The dose of ropivacaine was based on past experience and literature on its use in this population. ${ }^{13}$ The paravertebral block was performed with a $22 \mathrm{G}$ Touhy needle under aseptic conditions. The thoracic vertebral transverse processes were used as landmarks. The needle was inserted perpendicular to the skin, i.e., at a $90^{\circ}$ angle. Given the risk of puncturing the pleura, the needle was withdrawn and redirected caudally if the transverse process was not contacted at $3 \mathrm{~cm}$ on the first attempt. Then the needle was reinserted to $3 \mathrm{~cm}$. After locating the transverse process, the needle was moved off the cephalad or caudal edge of the process and advanced 1-2 cm further into the paravertebral space. ${ }^{14}$ The paravertebral space was identified by loss of resistance technique and lack of cerebrospinal fluid (CSF) or blood with aspirate. Both SPVB and Control patients had a bandaid placed over the $\mathrm{T}_{11}, \mathrm{~T}_{12}$, and $\mathrm{L}_{1}$ levels on the right paravertebral site. Ketorolac $0.5 \mathrm{mg} \cdot \mathrm{kg}^{-1}$ iv (maximum $30 \mathrm{mg}$ ) was administered at the end of the surgery, and acetaminophen $20 \mathrm{mg} \cdot \mathrm{kg}^{-1} \mathrm{po} / \mathrm{pr}$ was administered every $6 \mathrm{hr}$ for the first $24 \mathrm{hr}$. The surgical wound was not infiltrated with local anesthetic agent. Postoperative pain assessment was standardized and was determined through use of a ten-point visual analogue scale (VAS). The VAS was obtained by asking the patients to point to a specific position representing their current pain level on a line between two end points. The position was then converted to a scale where zero represented no pain and 10 signified maximum pain. Patients in both groups were given morphine $0.05 \mathrm{mg} \cdot \mathrm{kg}^{-1}$ $i v$ every $2 \mathrm{hr}$ if $\mathrm{VAS}$ was $\geq 5 / 10$. Time to first dose of morphine after surgery, total dose of morphine required in $24 \mathrm{hr}$, and any adverse effects, including nausea, vomiting, hypotension, or respiratory depression during the first $24 \mathrm{hr}$ after surgery were recorded.

The primary outcome variable was postoperative morphine requirements in the first $24 \mathrm{hr}$. The sample size (18 per group) was based on a two-sided accepted alpha error of $5 \%$ and an accepted power of $90 \%$, and the predicted reduction in morphine requirements was a 
relative reduction of $50 \%$. Binomial data, e.g., gender, were compared with Chi square analysis. Normally distributed continuous data, e.g., age, were compared with Student's $t$ test. Non-normally distributed continuous data, e.g., time to first dose of morphine, were compared with Mann-Whitney U test.

\section{Results}

Both groups had similar demographic data (Table 1). Patients in Group I (SPVB) required less morphine in the first $24 \mathrm{hr}$ after surgery than patients in Group II (Control) $(P<0.001)$ (Table 1$)$. The time to the first dose of morphine was significantly longer in Group I than in Group II $(P<0.001)$ (Table 2).

Two patients (11\%) in Group I developed vomiting compared with five patients $(27 \%)$ in Group II $(P=0.21)$ (Table 2). There were no other adverse effects (hypotension or respiratory depression) observed in the two groups.

\section{Discussion}

This study shows that somatic paravertebral block (SPVB) provides better pain relief in children after open appendectomy. Pain intensity was assumed to be directly related to total morphine requirements in the first $24 \mathrm{hr}$ and inversely related to the time to first dose of morphine. Patients who had a SPVB had reduced opioid requirements and a longer time to first postoperative dose of morphine. We could not demonstrate a decreased incidence of undesirable side effects, but this could be because of the small number of subjects involved.

While our knowledge of SPVB use in children is limited, the technique has been demonstrated to be a successful adjunct to general anesthesia for thoracotomies and urological surgeries in the pediatric population..$^{2-4}$ Several studies have demonstrated, as we have, that significantly lower morphine is required in patients receiving SPVB. In children undergoing urological surgery, the use of SPVB decreased morphine requirements significantly., ${ }^{2,3}$ Moreover, Naja et al. demonstrated that systemic analgesia

Table 1 Demographic data

\begin{tabular}{lll}
\hline & Group I (SPVB) & Group II (Control) \\
\hline Gender (male/female) & $10 / 8$ & $11 / 7$ \\
Age $(\mathrm{yr})$ & $10.1 \pm 3.0$ & $10.6 \pm 2.9$ \\
Weight $(\mathrm{kg})$ & $35 \pm 15$ & $46 \pm 17$ \\
\hline
\end{tabular}

Values listed are $\mathrm{n}$ or mean \pm standard deviation $(\mathrm{SD})$. SPVB $=$ somatic paravertebral block requirements in children undergoing inguinal hernia repair were significantly lower for children receiving SPVB compared with those receiving tramadol hydrochloride or propacetamol hydrochloride. ${ }^{5}$

Side effects of morphine use in children include nausea and vomiting, inadequate analgesia, urinary retention, pruritus, dysphoria, hypoxemia, and difficulty in arousal. ${ }^{15}$ While there was no statistically significant difference in vomiting in the Control and SPVB groups in our study, there was a trend towards decreased vomiting in the SPVB patients. Lack of significant difference may be attributable to an inadequate sample size; the study was simply not designed to make conclusions regarding side effects. However, given the trend in our study, it seems likely that incidence of vomiting would have been significantly lower in the SPVB group had sample size been increased. In similar studies, both Berta et al. and Naja et al. observed a $12-17 \%$ incidence of postoperative vomiting after SPVB, which was less than the incidence of vomiting after standard analgesia. ${ }^{4,5}$ The profile of SPVB side effects, specifically vomiting, appears to be less severe than that of morphine used alone.

The subjects in the current study received multimodal analgesia. This approach would be expected to decrease analgesia requirements in both groups. It is possible that the multimodal analgesia used in the current study may have acted synergistically with our intervention, i.e., SPVB, and exaggerated the differences noted between our study groups. The opposite could be argued as well. It is also possible that alternative multimodal analgesic approaches, such as local anesthetic infiltration and perioperative GABAergic agents, e.g., pregabalin, may yield results comparable with SPVB. Intranasal ketorolac has recently become available and has been demonstrated to decrease morphine requirements and to reduce overall pain levels when used postoperatively. ${ }^{16}$ Also, gabapentin-type drugs, including pregabalin, ${ }^{17}$ as well as local anesthetic injection at the surgical site ${ }^{18}$ have been demonstrated to be effective in multimodal analgesia. It is likely that the combination of drugs used in our study provided similar combined analgesic effects to both study groups. The use of SPVB in conjunction with other forms of analgesia appears to be an effective form of pain management, which simultaneously decreases adverse effects of opioids and other analgesics. ${ }^{19,20}$

There are a number of previously reported benefits of SPVB use in children. For instance, Naja et al. noted significantly reduced length of hospital stay in patients receiving SPVB. Another study conducted by Naja et al. demonstrated significantly higher overall parental satisfaction with SPVB use, as well as a higher proportion of sameday discharge in the SPVB group relative to general anesthesia combined with systemic analgesia. ${ }^{6}$ While these 
Table 2 Opioid use in postoperative period

\begin{tabular}{llll}
\hline & $\begin{array}{l}\text { Time to first } \\
\text { dose of } \\
\text { Morphine (hr) }\end{array}$ & $\begin{array}{l}\text { Total dose } \\
\text { of morphine } \\
\text { in 24 hr }\left(\mathrm{mg} \cdot \mathrm{kg}^{-1}\right)\end{array}$ & Vomiting \\
\hline Group I (SPVB) & $7.1 \pm 4.4$ & $0.12 \pm 0.07$ & $2(11 \%)$ \\
Group II (Control) & $2.5 \pm 1.6^{*}$ & $0.34 \pm 0.15^{*}$ & $5(27 \%)$ \\
\hline
\end{tabular}

$* P<0.001 ; \mathrm{n}=18$ /group. Values are $\mathrm{n}$ or mean \pm standard deviation $(\mathrm{SD}) . \mathrm{SPVB}=$ somatic paravertebral block

are clear benefits of the technique, potential complications of SPVBs, including hematoma and/or pain at the site of injection, vascular puncture, pneumothorax, hypotension, ${ }^{21}$ and total spinal block, ${ }^{22}$ have been noted in previous studies. Lonnqvist and Olsson, for instance, noted one case of pleural puncture in their pediatric study, ${ }^{2}$ while $8.3 \%$ of children in a study conducted by Berta et al. suffered vascular punctures. ${ }^{4}$ No such complications were noted in our study. Similarly, neither Naja and Lonnqvist nor Eng and Sabanathan observed these adverse effects of SPVB in children. ${ }^{3,21}$ Therefore, while precautions must clearly be taken to reduce potential complications of the technique, it appears generally safe and beneficial in the pediatric population.

Epidural analgesia is considered by many to be the best option for pain relief after major abdominal and thoracic surgery. A number of studies have compared the SPVB technique to conventional epidural analgesia. Lonnqvist and Olsson compared SPVB and lumbar epidural blocks in children undergoing major renal surgery. The total amount of supplemental morphine provided to patients and the number of patients requiring no morphine was significantly lower in patients who received SPVB. ${ }^{2}$ Similarly, Davies et al. performed a systemic review and meta-analyses of patients undergoing thoracic surgery and found that the side effects associated with SPVB were significantly lower than those following epidural anesthesia. Specifically, hypotension, urinary retention, failed blocks, and pulmonary complications were significantly lower in the SPVB group. The authors found that pain relief was similar in both groups. ${ }^{23}$ Therefore, SPVB appears to provide analgesia that is either equal to or greater than conventional epidurals while simultaneously offering a superior side-effect profile.

Unfortunately, blinding in studies such as ours is difficult. Only patients who received a SPVB actually had a needle inserted. For ethical reasons, it was considered unacceptable to insert a block needle and inject placebo, e.g., normal saline, into the Control subjects. To minimize bias, the anesthetic technique was very rigid. The nurses who evaluated our outcome variables were blinded by the use of bandage at the site of needle insertion.

In conclusion, SPVB use in children appears to offer improved postoperative analgesia with fewer side effects than morphine. In light of recent advances in ultrasound and nerve stimulator guidance used during SPVB, the technique may indeed become more user-friendly and thus more popular in the coming years. At present, this method is not used often in children; nevertheless, it is a worthwhile simple and effective alternative to provide improved patient recovery patterns in the pediatric population.

Acknowledgement The authors would like to acknowledge the significant contributions made by the late Dr. Khalid Chowdary.

Competing interests None declared.

\section{References}

1. Johnson CM. Continuous paravertebral block in children. Anaesthesia 1993; 48: 93.

2. Lonnqvist PA, Olsson GL. Paravertebral vs epidural block in children. Effects on postoperative morphine requirement after renal surgery. Acta Anaesthesiol Scand 1994; 38: 346-9.

3. Eng J, Sabanathan S. Continuous paravertebral block for postthoracotomy analgesia in children. J Pediatr Surg 1992; 26: 556-7.

4. Berta E, Spanhel J, Smakal O, Smolka V, Gabrhelik T, Lonnqvist $P A$. Single injection paravertebral block for renal surgery in children. Paediatr Anaesth 2008; 18: 593-7.

5. Naja ZM, Raf $M$, El Rajab M, Ziade FM, Al Tannis MA, Lonnqvist $P A$. Nerve stimulator-guided paravertebral blockade combined with sevoflurane sedation versus general anesthesia with systemic analgesia for postherniorrhaphy pain relief in children: a prospective randomized trial. Anesthesiology 2005; 103: 600-5.

6. Naja ZM, Raf $M$, El Rajab $M$, et al. A comparison of nerve stimulator guided paravertebral block and ilio-inguinal nerve block for analgesia after inguinal herniorrhaphy in children. Anaesthesia 2006; 61: 1064-8.

7. Ross AK, Eck JB, Tobias JD. Pediatric regional anesthesia: beyond the caudal. Anesth Analg 2000; 91: 16-26.

8. Richardson J, Lonnqvist PA. Thoracic paravertebral block. Br J Anaesth 1998; 81: 230-8.

9. Terheggen MA, Wille F, Borel Rinkes IH, Ionescu TI, Knape JT. Paravertebral blockade for minor breast surgery. Anesth Analg 2002; 94: 355-9.

10. Klein S, Bergh A, Steele SM, Georgiade GS, Greengrass RA. Thoracic paravertebral block for breast surgery. Anesth Analg 2000; 90: 1402-5.

11. Giesecke K, Hamburger B, Jarnberg PO, Klingstedt C. Paravertebral block during cholecystectomy: effects on circulatory and hormonal responses. Br Med J 1988; 61: 652-6.

12. Klein SM, Greengrass RA, Weltz C, Warner DS. Paravertebral somatic nerve block for outpatient inguinal herniorrhaphy: an expanded case report of 22 patients. Reg Anesth Pain Med 1998; 23: 306-10.

13. Eck J, Cantos-Gustafsson A, Kinder-Ross A, Lonnqvist PA. What's new in pediatric paravertebral analgesia. Tech Reg Anesth Pain Manage 2002; 6: 131-5.

14. Cousins MJ, Bridenbaugh PO. Neural Blockade in Clinical Anesthesia and Management of Pain, 3rd ed. Lippincott-Raven; 1998: 477-8

15. Esmail Z, Montgomery C, Courtrn C, Hamilton D, Kestle J. Efficacy and complications of morphine infusions in postoperative paediatric patients. Paediatr Anaesth 1999; 9: 321-7. 
16. Moodie JE, Brown CR, Bisley EJ, Weber HU, Bynum L. The safety and analgesic efficacy of intranasal ketorolac in patients with postoperative pain. Anesth Analg 2008; 107: 2025-31.

17. Agarwal A, Gautam S, Gupta D, Agarwal S, Singh PK, Singh U. Evaluation of a single preoperative dose of pregabalin for attenuation of postoperative pain after laparoscopic cholecystectomy. Br J Anaesth 2009; 101: 700-4.

18. Pogatzki EM, Vandermeulen EP, Brennan TJ. Effect of plantar local anesthetic injection on dorsal horn neuron activity and pain behaviors caused by incision. Pain 2002; 97: 151-61.

19. Buvanendran A, Kroin JS. Multimodal analgesia for controlling acute postoperative pain. Curr Opin Anaesthesiol 2009; 22: 588-93.
20. Kehlet H, Dalh JB. The value of "multimodal" or "balanced analgesia" in the postoperative pain treatment. Anesth Analg 1993; 77: 1048-56.

21. Naja Z, Lonnqvist PA. Somatic paravertebral nerve blockade. Incidence of failed block and complications. Anaesthesia 2001; 56: 1181-8.

22. Lekhak B, Bartley C, Conacher ID, Nouraei SM. Total spinal anaesthesia in association with insertion of a paravertebral catheter. Br J Anaesth 2001; 86: 280-2.

23. Davies $R$, Myles P, Graham J. A comparison of the analgesic efficacy and side-effects of paravertebral vs epidural blockade for thoracotomy-a systematic review and meta-analysis of randomized trials. Br J Anaesth 2006; 96: 418-26. 